\title{
4. Methodology: Doing Research in an Intersectional Field
}

\subsection{Applied Methods}

\subsubsection{Introduction: A Mixed Methods Approach in a 'Field without Sites'}

Developing a methodology for this project has been a challenging task, and its evolution was more often pressed upon me by 'the field' rather than chosen based upon methodological literature. It needed to be geared towards the question of how discursive gaps can be addressed that are produced through multilayered systems of discrimination. How - and where and when - can queer migrant women in Switzerland be addressed in terms of a self-representation rather than in terms of a mere deconstruction of the multiple mechanisms of exclusion through which intersectional subjects become othered? Given that analyses of dominant discourses in Switzerland only allow for insights as to how queer migrant women are systematically absent from both discourses around lesbians and migrants, and given that there were hardly any designated spaces for queer migrant women in Switzerland such as organizations, events, websites, and so on, the research unfolded in a 'field without sites' (see Chapter 2.3.3). This rendered dissipated personal interactions between queer migrant women and myself the only sites where queer migrant women's self-conceptions, experiences, and everyday practices - and the ways in which these are constrained - could be addressed.

As Jacqui Gabb writes: "Case study analysis is a useful starting point [to illustrate] how biography, experience, social processes and normalizing discourses shape, and are shaped by, everyday interactions" (Gabb 2009:49). But exactly on what kind of empirical data should such a case study rest? Following Gabb's 'qualitative mixed methods approach,' the methodological design for this study was conceptualized as a toolbox. ${ }^{1}$ Which tools ended up being used hinged upon on-the-spot choices and adaptations both on the part of the research participants and myself. Mixing qualitative methods

In an argument similar to Gabb's, Keith Woodward, John Paul Jones III, and Sallie A. Marston suggest using "methodological bricolage" and to "work with what it is hand" to address methodological problems that arise from working with ontological frameworks (Woodward et al. 2010). 
in this way served two aims in particular: First, methodological flexibility was meant to accommodate interviewees' preferences and reservations, which proved critical in generating a sufficient sample size. Second, mixing methods meant looking at cases from different perspectives, thereby attempting to prevent automatic reiteration of knowable identities. As Gabb points out, "subjectivity [of the research subject] cannot be readily reconstructed from the fragments of Self that are presented in research. Our interpretations remain partial and are grounded in the ways that we know ourselves" (ibid:48, emphasis original, see also Rose 1997). Gabb accordingly cautions against "tidying up all the empirical loose ends" in case studies; instead, she calls for retaining "some of the 'messiness' that comprises connected lives" (ibid:37). Indeed, a mixed methods approach generates productive juxtapositions that emphasize this partiality and messiness:

Pulling together the threads [of a research participant's] data does not create a single picture so much as many constitutive interdependent pictures: a family, a father, a son, a man and so on. Thematic analysis [gender, generation, etc.] can freeze the frame, conjuring up series of analytical snapshots but these comprise momentary meanings that disappear as quickly as they emerge, as the patterning of relational threads take on new formations. Throwing a whole bundle of methods at a subject does not decipher hitherto opaque processes, it is not new methods per se or novel combinations of methods which generate insight, greater understanding is instead afforded through attentiveness to the subtle interplay of threads which criss-cross the breadth and depth of data. Patterns among threads are sometimes readily apparent and at other times fleeting and intangible, focusing on the different ways that they are woven together evinces the contingency of lived lives. (Gabb 2009:49, emphasis original)

I was, on the one hand, interested in such a "thematic analysis," for as Gabb rightly contends, "tracing themes [...] remains an analytical imperative if studies are to add to knowledge of social phenomena." On the other hand, I wanted to work towards an understanding of the "living of lived lives" and the attendant "emotional messiness, uncertainties and fluidity that constitute relational experience" (ibid:49). I contend that the latter is particularly prominent in the narrations of interlocutors who inhabit intersectional subject positions targeted by multiple mechanisms of exclusion.

In her research on family relationships, Gabb uses seven different qualitative methods, giving research participants the choice which activities they wanted to engage in. It is especially this openness - leaving the choice of method to the participant, and with no ambition for all participants to complete all 'tasks' - that distinguishes Gabb's from other method triangulations. In my own study, openness was generated in a slightly different way. Originally, the toolbox I put together to address these issues contained two main methods, but more were in store. Although I formulated a 'standard procedure' (see below), I never meant to adhere to it strictly but rather intended to accommodate sensitivities, preferences, reservations, or simply a lack of time on the participant's part. Such concerns materialized aplenty in the course of the research. One interviewee insisted on being interviewed with her partner; another suggested taking a walk together to the places she had been talking about instead of taking pictures of these places autonomously as I had asked her to do; others did not find the time to take pic- 
tures but instead described to me what pictures they had intended to take; still others were generally reluctant to take pictures; and so on.

In the end, the triangulation of four qualitative research methods generated the data for this project. A combination of narrative biographical interviews and reflexive photography constituted the 'standard procedure,' while site visitation and participant observation were applied as additional methods. In alignment with the broader objectives of this project, the main focus was placed on generating a multilayered data set in collaboration with queer migrant women. These were contextualized by means of expert interviews with representatives from LGBT and immigrant organizations, immigration authorities and lawyers, as well as by attendance at (the few) panels held on issues of migration and homosexuality in this time. In sum, the 'field' here designated scattered spaces of interaction, not only with queer migrant women as primary research participants, but also with representatives from NGOs and the government, other 'experts,' potential door openers, and - not least - with colleagues working from different disciplinary perspectives, notably social anthropology, sociology, and history.

The 'standard procedure' envisaged two interviews per research participant. The first was a biographical narrative interview focusing on the participant's migration biography and everyday life in Switzerland. The second interview was based on reflexive photography. At the end of the first interview, participants were asked to "take pictures of places that are important to you in your everyday life" (this was the standard formulation of the 'task'). These pictures formed the basis of the second interview, which focused on why participants had taken pictures of these specific places and what these places meant to them. Participant observation was applied in a necessarily unsystematic way. Since there was a lack of public or semi-public spaces in which queer migrant women could be met as such, I could not simply 'hang out where they did,' as one might do when researching, say, the organizing of South American migrant women in Switzerland. ${ }^{2}$ In other words, participant observation could mostly be pursued only after meeting with research participants for the first time, and necessarily remained uncertain since the extent of further meetings hinged upon mutual sympathies, interests, time resources, and opportunity. Sometimes there were upcoming events that could be attended together or to which I was invited - for example, gay pride parades or birthday parties. In other instances, I was able to visit interviewees at their public workplaces, for instance in restaurants. In contrast to fieldwork 'out there,' my 'field' was moreover entangled with my everyday routine; consequently, the possibility of meeting was also restricted by my own everyday obligations (meeting interviewees most of the time meant traveling to another city). Finally, site visitation was a method that was not envisaged in the original design but simply 'happened' as research participants sometimes spontaneously suggested we visit places they were talking about in the interviews or that they had photographed or intended to photograph.

2 Nevertheless, I did frequent places in which there was an increased likelihood of meeting queer migrant women (or people who might know queer migrant women), especially lesbian clubs and events, see Chapter 4.2. 


\subsubsection{Biographical Interviews}

The main condition of how people in the West are supposed to understand themselves is the obligation to construct a coherent identity, also a biography, a curriculum vitae; this is, so to speak, the ultimate condition for the existence of modern subjects. Even if structuralism has completely annulled exactly this requirement - the consistent/autonomous construction of identity - it is by far not dispelled in everyday perceptions, knowledge and actions. You are dealing with a group [of study participants] which is, so to speak, a prime example of fragmented identities - the discontinuities lay open, and are probably more determinative of identity than any search for 'coherence.' (Sabin Bieri, pers. comm. (e-mail), emphasis original, my translation)

My colleague Sabin Bieri's pointed comment above was in response to an early proposal for this research. It signposts the paradox of the position research participants with 'fragmented identities' occupy vis-à-vis the concept of biography. In accordance with Bieri, biography researchers Wolfram Fischer-Rosenthal and Gabriele Rosenthal contend that biographical competence is compulsory for all members of a society and is a "central means by which we orient ourselves and interact in many social situations in modern societies" (Fischer-Rosenthal and Rosenthal 1997:405, my translation). The authors define biography as a cultural concept that performs a double act pivotal to the negotiation between individual and society: "Societies of modern times have developed biographical structuration to individualize and integrate their members" (ibid, emphasis added). Biographical work is requested in a myriad of social interactions: job interviews, small-talk at cocktail parties, therapy sessions, asylum procedure, and so on. Depending on the context, the biographer reconstructs her own past selectively, thereby positioning her present Self in relation to others. At the same time, the structure of the narration is crucially guided by the schemes predefined by institutions and other collectivities. Biographies are therefore by no means fixed narratives about a frozen past but, as Bettina Dausien argues, active self-positionings in which "things past and future, experience and expectation, retrospection and prospection constantly intertwine" (Dausien 2000:102, my translation). Biography researchers accordingly analyze biographical narratives as a "social construction suspended between structure and practice, which, with respect to the conditions of its emergence and in its concrete forms, is always tied to a specific historical-social context" (ibid:100). The biographical narrative is, on the one hand, an expression of subjectivity: a momentary, situated, and situational story of the Self, grounded in reconstructed memories of the past, contingencies of the present, and visions of the future, and represents a process of positioning the Self in relation to others. On the other hand, the biographical narrative is always also an expression of the multi-dimensional social conditions from which it emerges. Since the biography is always a simultaneously individual and social product, its analysis allows for a reconstruction of the interlinkages between individual, subjective storytelling and collective processes:

By means of biographical narratives it becomes possible to analyze the intersections of individual and society and to point to the significance of collective [...] pasts. In this 
context, it has to be emphasized that the individual story of a person as well as the interpretative retrospection of the past constitutes itself from the dialectics between the individual and the social. (Rosenthal 2005:61, my translation)

Located at the nexus of individual and society, biographical narratives always perform 'identity work'; their analysis, therefore, allows for an examination of processes of (dis)identification (see Chapter 3.4.7). In her call for more ethnographic approaches in intersectionality research, Gill Valentine (2007) analyzes interviews in order to understand the dynamics of the moments in which certain social categories become relevant in biographical narratives, and how a biographer's different identities - such as being a lesbian, a woman, and so on - may reinforce, weaken, or be in conflict with one another across time and space (see also Dausien 1996). Valentine argues that "we may think of class, race, and gender as different social structures, but individual people experience them simultaneously" (Valentine 2007:13, emphasis added). She identifies the biographical interview as one instance in which this simultaneity becomes manifest. Having said that, in the quoted article Valentine's categories do seem predefined and quite fixed. In terms of analyzing the ways in which social categories play out in narratives, I rather adopt Kath Weston's perspective, stating that "I am not interested in these categories [class, gender, language, and others] as demographic variables, or as reified pigeonholes for people, but rather as identities meaningful to participants themselves. I concentrate here on the interpretive links participants made (or did not make) between sexual identity and other aspects of who they considered themselves to be [...]" (Weston 1997 [1991]:11-12). In general, we need, first, to strive to be rigorously reflective about bringing already-known identity categories to analyses of processes of identification, especially if so-called 'intersectional' subject positions are involved. Second, we need to expect to be told a completely different story featuring other 'variables' and logics than we would have imagined.

Third, we need to consider Jasbir Puar's radical critique of how we have been theorizing identities. Race-class-gender (and so on), she contends, are components, but identification a spatio-temporal process (see Chapter 3.4.7). Translated to the interview context, this means that the biographical narrative not only exposes but also presently performs the interpretive frame through which the speakers perceive themselves, the world, and their place and actions in it. In other words, identities do not preexist their performance. Interviews are therefore never mere reifications of already existing identities, and neither are interviews as processes of identification only about 'pulling stops' (race! class! gender!). Instead, they always also intervene in the constant reconfiguration of identitarian stories-so-far (see Chapter 3.1.1).

As Geraldine Pratt argues, such interventions are particularly prone to emerge from the movement of bodies through space, as for instance happens when people migrate from one place to another: "Managing [...] contradictions, or bringing one discourse into relation with another, can open points of resistance. [...] Moving through places may involve moving between discursive formations and be one way that individuals become aware of the contradictions between discourses" (Pratt 2004:20). Narratives by migrant subjects and generally by individuals who inhabit intersectional subject positions are hence particularly likely to be marked by representational crises and discontinuities 
that fail to be described by the 'sum' of their 'identity components.' In addition to examining the ways in which identities emerge as relevant to biographical analyses, the subsequent analysis accordingly places a particular emphasis on analyzing exactly such contradictions, hesitations, ruptures, and slippages that mark resistances against, and failures to reproduce, dominant formulations of identity categories.

As Bieri and Rosenthal point out, doing biography as done here is a cultural concept of "the West" (Bieri) and "modern society" (Rosenthal), which raises questions about the usefulness and justification of the method in intercultural interview settings. Although different societies are productive of different conditions of existence that may or may not include the Western requirement of ceaseless biographical performance and biographical coherence, I assumed - possibly problematically so - that, as immigrants, interlocutors would necessarily have had to develop such a biographical competence through their migration. At the same time, the generally high level of education in the sample may indicate reservations on the part of less-educated potential research participants to tell their story (moreover in a foreign language and with a declared focus on intimate issues). Generally, participants - especially highly educated professionals and members of the middle and upper classes - mostly (but not always!) felt reasonably comfortable to talk about their life stories in the sense of a biographical narratives.

However, it is important to remember that in many cases this competence has been shaped by immigration or asylum procedures. In these procedures, the rule of biographical consistency becomes particularly salient and sometimes existential as immigrants and asylum seekers (particularly those from non-Western countries) are forced to present themselves as appropriately unthreatening, subservient, and assiduous to obtain the desired visa/asylum in Switzerland. Here, the presentation of a Self that is both biographically consistent and legible to the raster of one of the few narrowly defined subject categories in Swiss immigration and asylum legislation can be a matter of life and death. While this rule of consistency and legibility applies to 'regular' immigrants to a much lesser extent than it does to asylum seekers, the requirement of coherence remains in essence the same. And it persists after crossing the border, for instance in job application processes, social services, the welfare system, residence permit renewals, and so on.

Bearing all this in mind, in conducting the narrative-biographical interviews, I have largely followed Gabriele Rosenthal's suggestion (1995) to structure the procedure in four parts: an open invitation to narrate, a main biographical narration, internal follow-up questions based on notes taken during the narration and external follow-up questions, and a conclusion. Following this design, a broad initial question was used to elicit the narrative ("Can you tell me the story of how you came to Switzerland - from the moment when you first started considering leaving your country?"). ${ }^{3}$ The ensuing

3 This question differed in the few cases in which I interviewed women who were born and grew up in Switzerland or who came to Switzerland as children. This question was not standardized but depending on the specific positionality of the interviewee for instance included "First I would like to ask you to just tell me a little about who you are and what you do." 
narrative was interrupted only by questions aimed at clarification. In a second phase, follow-up questions asked for more detail concerning some issues mentioned in the first part. Departing from Rosenthal's script, the third phase of the interview then drew on an interview guideline in order to address issues that had not been brought up in the conversation-so-far. To conclude the interview, interviewees completed two forms asking about objective data (date of birth, education, status of residence, date of arrival in Switzerland, marital status, etc.) and habitus (family members' and partners' education, profession, place of residence, religion, etc.).

\subsubsection{Reflexive Photography}

Visual methodologies are, astonishingly, a latecomer to ethnographic research in social geography. This despite cultural geographers' early insight that "the very heart of geography - the search for our sense of place and Self in the world - is constituted by the practice of looking and is, in effect, a study of images" (Aitken and Zonn 1994:7, see also Cosgrove 1985, Rose 2003). While the study of visual representations of the world has long been established in the field of critical cultural geography (Barnes and Duncan 1992, Cosgrove and Daniels 1988, Duncan and Ley 1993, Rose 2001, Said 1978), visual ethnographic geographical research only found its way into the mainstream of the discipline in the course of the 'visual turn' propelled by more easily accessible technologies such as the smartphone - which had only just started to feature cameras when this research began - and the internet (Crang 2003, 2005, and 2010, Dodman 2003, Dirksmeier 2007:2, Hörschelmann 2007, Kindon 2003, Rose 2003, Thomas 2005). In ethnographic migration studies, on the other hand, the absence of visual methods remains pronounced. This is particularly surprising in queer migration studies considering that queer diaspora studies have established a rich tradition of analyzing visual material (Gopinath 2005, Muñoz 1999).

In this study, I have applied reflexive photography in order to gain an understanding of the imaginative geographies by which queer migrant women define themselves and their place in the world, and by which they live their everyday lives. In reflexive photography, participants are asked to autonomously take pictures in relation to a certain aspect of their lives and are subsequently requested to interpret their photographs in an interview (Dirksmeier 2007:1). Peter Dirksmeier argues that it is the specific characteristics of photography as an image-producing practice and the photograph as an image that make photography particularly interesting for social scientific methodologies. After all, photography is a widely distributed, low-threshold, and therefore relatively democratic practice in industrialized regions around the world, with virtually every portable electronic device now featuring a camera. Second, photography is unique in its function as a "visibility isolation machine" ("Sichtbarkeitsisoliermaschine") which detaches the visibility of a material object from its physical substance. A photograph is thereby characterized by exactness, that is an exceptionally far-reaching similarity between the object as depicted on the image carrier (image object-i.e. the photograph of a person) and the physical object it represents (image subject - i.e. the person). In 
other words, a photograph creates a particularly predictable rendering of an image subject (ibid:5, quoting Wiesing 2005:162). ${ }^{4}$

Dirksmeier frames the photo and photography as a thoroughly structured system of meaning and practice, arguing that "reflexive photography takes advantage of the evaluative and classificatory relationship subjects have to their environment, which is intricately linked to the act of taking pictures." He accordingly describes the taking of a photograph as a highly selective process. Who photographs what, when, where, and how is highly contingent on the "principle of the before-known image." This means that the photographer effectively looks for a pre-conceived image in reality; the photograph thus represents a physical realization of a mental image and thus an objectivization of the subjective gaze when the image is viewed, since the image object can be related back to the image subject (Dirksmeier:5-6, referring to Wiegand 1981:8).

Dirksmeier does not imply that the researcher can read the image 'for what it is' in any transcendent way, which is why the method of reflexive photography emphasizes participants' interpretation of the image and the researcher's subsequent analysis of the narrative about the image (rather than of the image itself). Nor does Dirksmeier insinuate that taking a picture can ever be a fully controlled or known process: "Photographic images owe their characteristics to the fact that actors are not permanently conscious about the full meaning of their practices, while their practices are at the same time inhabited by more meaning than they know or want to know," he notes (Dirksmeier 2005:6). In other words: First, taking a picture can never be a fully controlled process, as the photographer can never fully know her intentions behind taking a specific picture. Also, it is not only the "before-known image" that determines where and when the shutter is pressed. The world often presses images onto the photographer, too - a butterfly sailing through an open window; or think of the first seemingly haphazardly cropped photographs a small child takes of something which has just caught her eye in the spur of the moment. This immediacy is facilitated by the fact that taking photographs is an exceptionally fast, almost instant, way of producing images. Second, photography always produces an excess of image objects. While the photographer decides, more or less consciously, what picture is taken, the resulting image will always also depict things that were not part of the "before-known image." These excess things carry the potential to gain significance in the later viewing in the context of the research interview.

A further reason that Dirksmeier does not mention but which was instrumental in my decision to apply reflexive photography (instead of mental maps, for instance, see Jackson 1995 [1989], Tuan 1975), was that, unlike other forms of image production, photography mostly requires the photographer to be materially present at the site, in view of (but necessarily also distanced from) the image object. In accordance with an ontological approach to space, my interest lay in research participants mapping their everyday spaces and practices in Switzerland while being caught up in them, rather than obtaining retrospective and therefore necessarily more distanced, organized, and reflected maps from memory. (However, as discussed below, this partly failed.)

In sum, taking a photograph is informed, but never entirely determined, by the photographer's "before-known" image. The meaning of the picture remains contingent 
on its viewing and necessarily shifts, as "photography is the contextualized re-enactment of seeing [the past], rather than a means of freezing it" (Meinhof and Galasinski 2000:327, quoted in Felber Rufer 2006:67). As such, viewing images is always also a process of identification. Both taking and viewing photographs are as much expressions of a structured system of meaning as they are a messy and embodied set of practices (the speed of the technology; the photographer's eventual lack of control over a photo's contents; her physical entanglement in the sites photographed; the emotional charge of an image; the lack of words to describe what was meant to be conveyed in an image). It is precisely this meeting-up of planned and unplanned, structured and messy, representational and non-representational that renders reflexive photography an interesting tool to research imagined geographies and the lives lived based on them. From this view, the practice of photographing - taking, developing or uploading, distributing, and showcasing or viewing photos, in secret, at an interview, at a family gathering, among friends, on the desk at work, on social media platforms, and so on - is not a freezing of time and space but rather a dynamic process of identification in the 'throwntogetherness' (Massey 2005) of real and imagined spaces and places.

Beyond these fundamental aspects of taking and viewing photographs, four specific characteristics of the method of reflexive photography have informed my choice of the method. First and foremost, the autonomy that reflexive photography grants participants marks a change of perspective that promised to be particularly valuable in the context of a project addressing 'impossible subjects.' In reflexive photography, this change of perspective is particularly far-reaching as the participant not only controls the process of taking the photograph but also, at least to a certain extent, its interpretation as facilitated in the follow-up interview on the pictures taken. Reflexive photography therefore "allows for a great deal of contingency rather than rediscovering predefined orders by means of controlled methods. In this sense it is suited to at least partially avoid the weaknesses of 'conventional' [textual] quantitative and qualitative methods" (Dirksmeier 2007:8). Researchers applying other self-directed visual methodologies such as photo novella/diary or participatory video have equally defined this change of perspective as the main strength of such methods. David Dodman frames this type of method as "a direct method of empowerment, as the act of photographing requires 'putting oneself into a certain relation to the world that feels like knowledge - and, therefore, like power"' (Dodman 2003:294, quoting Sontag 1973:4). Sarah Kindon sees in this change of perspective a suitable method for working towards a feminist practice of looking 'alongside' rather than 'at' research subjects, which "challenge[s] conventional relationships of power associated with the [masculinist, ageist, colonialist, etc.] gaze in geographic research, and results in more equitable outcomes and/or transformation for research partners" (Kindon 2003:143). As such, these methods differ significantly from other visual methodologies such as photo elicitation where it is the researcher who provides the photos to elicit narratives (Felber Rufer 2006, Gabb 2009).

There is, however, a caveat to the use of reflexive photography as a change of perspective. Dirksmeier sees a particular strength in changing perspectives because the photographer's autonomy allows for the scientific observation of spaces that the researcher is otherwise excluded from. Lorraine Young and Hazel Barrett (2001) note in 
this context that self-directed photography yields images of situations that would have changed in the presence of the researcher-as-outsider. While all three authors evaluate this as one of the strengths of the method and as a possible answer to researchers' restricted access to certain spaces (Young and Barrett for instance research the life-worlds of Kampala street children), I remain ambiguous about this specific aspect. Given the spontaneity and exactness of photography, I agree that reflexive photography grants an intimate visual access to the spaces the photos depict. However, the camera might also be more pessimistically framed as an invisibilization machine which makes the researcher invisible. As such, it can grant the researcher 'access' to spaces inhabited by underprivileged subjects, some of whom may not welcome such visibility. As postcolonial scholars' critiques of photography in anthropology and geography have widely shown, visibility to researchers has all too often led to unfavorable readings of 'who they are.' It is, in my eyes, ethically less problematic to take advantage of the method to gain 'access' to exclusive, privileged social sites such as corporate boardrooms or luxury resorts, or to no-go sites, such as prisons or war zones. However, such research has remained rare, not only because the visual methods discussed here have been developed explicitly in the context of research focusing on deprivileged social groups but also because the former, privileged, spaces are also the ones where visual 'access' is much more controlled and successfully restricted. In short, in contrast to its explicit aim of 'giving a gaze' to underprivileged research participants, reflexive photography in some ways eventually remains complicit in the project of making visible and legible the Other while rendering invisible those in power. Despite the unquestioned strengths of the method - especially in comparison to other qualitative and quantitative methods - this caveat should not be neglected (as it often is) when doing research that involves deprivileged research subjects.

A second strength of reflexive photography is its supportive function in interview settings in which not the mother tongue, but a foreign tongue was spoken, which was often the case here. Although the focus was eventually on the verbal narrative participants offered about the photos, the pictures represented an additional, non-verbal means of expression that facilitated communication about the issues that interviewees tried to convey (Dodman 2003, Thomas 2009). The fact that the accounts about the photos sometimes contradicted narratives provided in the biographical interviews points to the effectiveness of the diversification of perspectives this method usefully enables (Thomas 2009:5).

The third aspect that rendered reflexive photography particularly useful in this research is that it enabled a discourse about spaces and places. Biographical interviews focus on the telling of life stories. Since these events necessarily 'take place,' an examination of biographical narratives always also allows for an analysis of the meanings of spaces and places these stories both draw on and produce. However, biographical interviews rarely yield explicit reflections about spaces and places, or about the mundane (Felber Rufer 2006). While it is usually not difficult to elicit (life) stories, it is much harder to direct an interview towards actions carried out in everyday spaces and places, or to speak directly about these spaces and places. Such narratives are often 'thin' and short, be it because interviewees think them too banal or because these practices are naturalized to an extent that their reflection is rendered impossible. Photographs of everyday places 
encourage participants to take a step back in order to reflect on these places and their practices in them, and in this way to indulge in narratives of the banal. As Dirksmeier notes: "The photos enable a deeper, more reflected thinking about the issues in question on the participants' part, which generates information which would not have surfaced without the preceding process of taking the photos" (Dirksmeier 2007:8).

The fourth and final advantage of reflexive photography is the simple fact that research participants usually consider it unconventional as a research method. As discussed below, especially in the context of migration studies involving immigrant interviewees who have undergone, or are still undergoing, arduous immigration or asylum procedures, biographical interviews can be saturated with ambivalence or even trauma. Beyond this, there is a risk of reproducing biographies geared towards immigration authorities in the research context. And while analyzing such 'rehearsed' biographies (which are not easily discernible as such) has been highly informative in this study in itself (see especially Chapter 8), it has been equally insightful to disrupt their flow by means of reflexive photography. Indeed, reflexive photography allowed participants to tell and frame things differently, and maybe less coherently, enabling deviations from reiterating normative or even coerced narratives of subjectivization.

The procedure of reflexive photography as it was used in this project was designed as follows: After the biographical interview, participants were provided with a one-way camera (if they could not provide their own camera or smartphone, which at the time rarely featured cameras), and were asked to take a minimum of one and a maximum of thirty-six pictures of "places that are important to you in your everyday life." These pictures were to be taken within a certain timeframe, usually two to four weeks, depending on the participant's time availabilities. The pictures then served as a basis for a second interview, which focused on why participants had taken pictures of these specific places and what they meant to them. In order to secure participants' anonymity and, related to this, in order to ensure the greatest possible spontaneity for the process of taking the pictures, I informed the research participants prior to taking the pictures that I would not publish any pictures without their explicit consent, and that I would not show them to anyone except the four colleagues I worked on the interview analyses with. I further assured them that I would mainly use their narratives about the images for my analysis and only occasionally provide a description of an image. This proved a worthwhile approach. Many of the submitted pictures were of an extraordinary intimacy, and in fact it was usually exactly this intimacy that made this space or place 'important.'

The remainder of this sub-chapter offers some preemptive considerations about the use of reflective photography in this project, which I believe are useful to be aware of before entering the interview discussions. When I started working with reflexive photography at the outset of the research, it quickly became evident that the method was not always going to work in the ways I had intended. Although participants had been provided cameras if needed and had been instructed according to a standardized set of instructions that had been defined on the basis of other research using this method, many interviewees selected pictures from their digital photo archives instead of actually taking pictures within the agreed timeframe. What worked smoothly in the fieldwork 
of a colleague of mine, whose work ran parallel to my own in a project concerned with the use of public parks by youths (Landolt 2011), did not seem to work as well in this project. Even considering that factors such as age or technological skills and affinities may have played a role in some cases in which interviewees were reluctant to take pictures, the pattern of selecting images from archives rather than taking them in material everyday spaces was too prevalent to be explained by these reservations alone. At first, I doubted my communication skills, but upon closer inspection, the narratives delivered about the images suggested that the alleged misinterpretations of the task were in fact deliberate. The original task was overruled by the relevance of imagined spaces in interviewees' everyday lives - distant places and people, and past times -, which could not be photographed in the given framework of the research. The urgency to include these imagined spaces in a collection of pictures showing "places important to you in your everyday life" became particularly evident in cases in which pictures of pictures, or pictures of computers (representing cyberspace, especially Skype) were taken. In other words: Participants worked against the grain of the method in order to represent what needed to be represented despite its literal physical absence.

Figure 4: The picture on the left was explicitly taken for the research with the research participant's smartphone. The picture on the right is from another research participant's photo archive. (Publication permitted by research participants.)
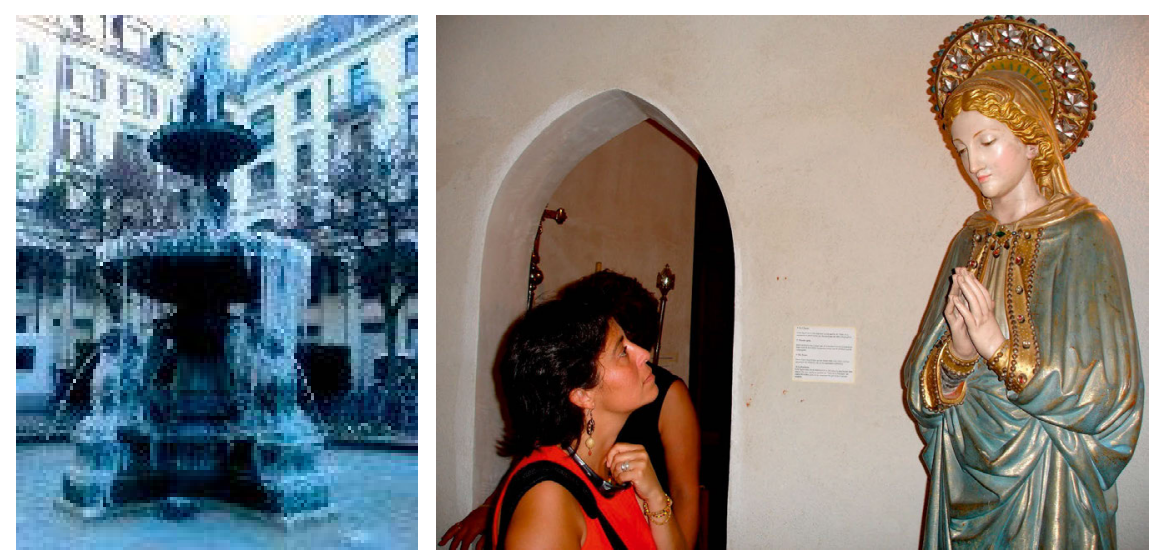

The point here is not to draw a demarcation between real (here: taken pictures) and imagined (here: pictures selected from archives) geographies. As Dirksmeier's conceptualization of the photo as a "before-known image" points out, all images are eventually realizations of imagined geographies, and the aim of applying the method of reflexive photography was to research these very imagined geographies. On the other hand, there remains a difference between the home-making performed by presenting pictures taken in everyday life and the home-making performed by presenting pictures from archives. The proliferation of pictures of (geographically and temporally) distant places and people that could not be photographed in everyday life signposts the relevance of 
these places and people as resources in everyday life or as sites of attachment for multifaceted homing desires that often could not be fully realized in 'material' everyday life.

Yet, in its very failure, reflexive photography eventually succeeded. The original proposed method of photographing 'real' places was revealed to be too constrictive for this transnational and intersectional context. Instead, interviewees' non-compliances emphasized the significant role that geographically and temporally distant people and spaces play in their lives, thereby providing insights that other methods would not have brought forth with such force. As such, the method indirectly but very effectively addressed the questions I had posed earlier, such as to what places interviewees attach a sense of home, given the absence of designated spaces for queer migrant women in Switzerland.

Similar insights could be gained from cases in which interviewees refused to take pictures. The arguments on which these refusals were based (which will be addressed in the discussion of each case) and what activities sometimes replaced the original method - sometimes a walk together to an interviewee's favorite places, sometimes detailed descriptions of the pictures interviewees would have taken - arguably yielded a better understanding of the case stories than the original method would have done. Perhaps a more general lesson from this outcome, then, is that the subject will tell her story (almost) no matter the method; and that the most important stories are in fact often told through the very deviation from a given method.

Beyond these unexpected but productive findings, the strengths of reflexive photography played out as expected. The unfamiliarity of the method - both for the interviewer and the interviewee - often resulted in hesitation, silence, and helplessness ("What else can I say?") in the interviews. In contrast to the biographical interviews, this produced conversations rather than one-way narratives, and the images themselves offered useful guides for both interviewer and interviewee. Letting both interlocutors talk to the printed photographs instead of to each other also to a certain extent removed the gulf between interviewer and interviewee. Interviewees' accounts of their pictures especially exposed the "emotional charge" images can carry and moreover pointed to the importance of the photograph as a tangible object with its own materiality (as discussed in more detail in Chapter 7).

The photographs and the accounts on them proved highly useful as 'keys' to the biographical narratives. It sometimes even seemed as if the photos and the attendant narratives were like a fluorescent marker highlighting the core concerns expressed in the biographical interviews. But sometimes they also contradicted earlier statements or suddenly made something visible that had been completely absent from the biographical interviews.

In sum, while the use of reflexive photography in this study has offered a glimpse of the still rarely tapped potential of visual ethnographic methods for migration research and other research addressing intersectional subject positions, it has also exposed that these very perspectives also challenge and extend the method. 


\subsection{The Sampling Process}

\subsubsection{Theoretical Sampling}

The search for participants was guided by the principle of Theoretical Sampling (Glaser and Strauss 1998 [1967], Strauss and Corbin 1998). This principle designs the sampling as an ongoing process. In practice this means that already transcribed interviews are subject to a preliminary analysis to determine what the characteristic of the next cases should be, whereby the next case can either aim to extend or contrast a specific finding. The procedure supports the understanding of all relevant aspects of an examined topic and research subject. For instance, in this study the theoretical sampling process yielded age, length of stay in Switzerland, age at migration, type of residence permit, educational level, employment, identification as 'lesbian' or not, and sexual self-definition prior to migration as some of the most salient factors structuring research participants' self-conceptions and migration biographies as well as their social positionalities, their everyday lives, and their wellbeing in Switzerland.

At the same time, the challenges faced in the search process pushed the limits of Theoretical Sampling so that, oftentimes, it remained just that - theoretical. Finding queer migrant women who were willing to take part in this study was a demanding endeavor. As discussed in Chapter 3.5, the problems started with the question of how to circumscribe the research subject, complicating the question of what terminologies should be applied to hail research participants. Another perplexing question was where to look for queer migrant women, seeing that there were hardly any designated spaces for them in Switzerland and indeed only scarce expertise about this subject position in general (see Chapter 2.3.3). The fact that certain kinds of people - such as members of the working class - remained largely absent from the research (despite efforts to establish a balanced sample in this respect) is arguably one result of these challenges and indicates areas for future research.

\subsubsection{Search Channels}

In accordance with the above, the sampling process could not always be carried out as planned and was often 'deviated' by the field. As this was a 'field without sites,' the search was necessarily guided by casual comments, chance encounters with door openers, leads pursued impulsively, participation in eclectic events, activities on virtual bulletin boards, unexpected snowball effects, remote personal contacts, and sympathies and affinities. The following list provides an overview of the places where I looked, and where the search was successful. As can be read in between the lines, the search process was arduous and halting because by no means did all search channels yield results. This was importantly owed to the fact that the organizations and institutions through which the search needed to take place did not address queer-and-migrant-and-women, and on part of these organizations and institutions often resulted in a denial of knowledge or expertise about, or a lack of interest in, the issue (see Chapter 2.3.3).

Search channels and loci included (with the number of participants found through each channel listed in parentheses): 
- My personal network - this mainly included Swiss queer/feminist academic and activist circles, the Swiss lesbian grapevine, and the eclectic mix of further acquaintances made throughout a life lived in three Swiss cities (six participants were found through this channel).

- News sections on NGO websites - mostly sites run by Swiss lesbian NGOs (five participants found) and two sites run by migrant NGOs (no participant found).

- Door openers - research participants themselves (snowball effect) (five participants found), representatives of lesbian and migrant NGOs (no participant found), and a journalist who had investigated queer Muslim women in Switzerland (one participant found).

- A brief article about my research, which also included a call for research participants, appeared in the Bern edition of zominuten, a low-prestige but very widely read commuter newspaper (three participants found).

- LGBT events and spaces - this included attendance at LGBT events on migration and homosexuality (two participants found), placement of the flyer at the Queeramnesty information stand at the gay pride event (no participant found), in lesbian clubs (no participant found), and in the offices of lesbian and other LGBT organizations (no participant found).

- Integration offices (Integrationsstellen) of all 26 Swiss cantons (e-mail) (two participants found).

- Immigration lawyers specializing in homosexuality and migration, one of whom mailed out the call to former clients in an anonymous mailing (one participant found).

- Lesbian chat sites with sizeable Switzerland-based communities (especially www.he r2her.ch, www.purplemoon.ch, and www.shoe.org) (two participants found).

- Internet search of publicly visible queer migrant women (two participants found).

- Migrant NGOs in Switzerland, many of which specifically focused on women (e.g. NOSOTRAS - Wir Frauen, Forum für einen fortschrittlichen Islam, and many others). These organizations were contacted by e-mail, followed up by a round of telephone calls and a mailing of multilingual flyers (German, French, English, Tamil, Albanian) and postcards (no participant found).

- Fachstelle Frauenhandel und Migration FIZ - a help desk advising trafficked migrant women. This collaboration failed due to concerns about anonymity and a self-declared lack of experience with queer women (no participant found).

- Civil registry offices (Standesämter) of Bern and Zürich - this collaboration eventually failed as well. My idea had been to have these offices send out an anonymous mailing to all non-Swiss or binational couples who had registered their partnership since this had become possible in 2007 (no participant found).

In order to contextualize the data generated in collaboration with queer migrant women, the following people, organizations, and governmental institutions were moreover contacted in search of experts on the issue of homosexuality and migration in Switzerland (as well as in search of potential door openers to further research participants): 
- Representatives of lesbian NGOs (LOS, L'Estime, Lilith, and others) and the few LGBT NGOs with the double focus on homosexuality and migration (e.g. Queeramnesty and SLAP).

- Immigration lawyers specializing in the issue of homosexuality and immigration.

- The officer responsible for gender-based persecution in the context of asylum at the Bundesamt für Migration BFM (Federal Office for Migration).

- Help desks for migrants, such as the Fachstelle Frauenhandel und Migration FIZ.

- Representatives of migrant associations and NGOs, with a focus on organizations run by immigrant women (Forum für einen fortschrittlichen Islam, etc.).

While some of these organizations and institutions reacted by rejecting any expertise on the issue, others were willing to collaborate, which sometimes also included granting atlength interviews. Such a multi-sited search renders the ex-post question of how these search sites, channels, and methods were structured (and hence the ways in which the sample may be biased) all the more important. This issue will be discussed throughout the data analyses.

\subsubsection{Interview Location}

Research participants were free to choose the location for the interview, which most often took place in their homes, but sometimes also at the Institute of Geography at the University of Bern, and on rare occasions in a restaurant. In order to both contextualize the interviews and to create a 'home advantage' for research participants, I found interviews at participants' homes most rewarding. Research participants were not recompensed monetarily. Interviews were held throughout German- and French-speaking Switzerland, including Zürich, Bern, Basel, Lausanne, and Luzern, and some smaller cities and villages.

\subsection{Data Corpus, Data Analysis, and Writing Process}

The data corpus generated by this study ultimately included audio recordings of 47 interviews with 28 queer migrant women from 22 different countries (biographical and reflexive photography interviews); case-based memos; field notes from participant observation; minutes taken in explorative interviews with a number of queer migrant women at the outset of the research; audio recordings and/or minutes from eight expert interviews, and from three podium discussions and symposia on the issue of homosexuality and asylum/immigration. Most interviews were conducted between autumn 2005 and spring 2009, with some additional interviews conducted in autumn 2013. Five research participants lived in French-speaking Switzerland, all others in Germanspeaking Switzerland; the study is hence biased towards the latter part of the country. (A detailed overview of the data corpus can be found in Annex I-II.)

The data analysis combined two methodological approaches. Rather than formulating and (dis)proving hypotheses, these approaches both sought to "gain empirically substantiated new insights and theoretical concepts about biographical processes and 
lived experiences in a specific field" (Dausien 1994:138-139). In explorative studies like this, such conceptual openness has proven to be of particular significance. The two approaches used here were the coding techniques of Grounded Theory (Glaser and Strauss 1998 [1967], Strauss and Corbin 1996) and reconstructive sequential analyses as formulated and applied by biography researchers. ${ }^{5}$ The data analysis was conducted according to the method developed in the course of a number of methodological workshops at the graduate school "Gender Scripts and Prescripts" at the University of Bern, which were taught by Bettina Dausien (see Dausien 1994 and 2007), Ulrich Oevermann (Oevermann 2002, Wernet 2000), Günter Mey and Katja Mruck (Mey and Mruck 1997), and Gabriele Rosenthal (Fischer-Rosenthal and Rosenthal 1997). The triangulation of Grounded Theory and reconstructive sequential analyses respectively allowed for both horizontal analyses, that is, for tracing themes across cases, as well as for vertical, in-depth analyses of single cases.

The data analysis was carried out in a four-step procedure. In the first step, the generated material - interview transcripts, field note entries, notes made while re-listening to the interviews repeatedly, photographs, and memos - were posted on a large wall. This resulted in a visual matrix, organized according to research participants' contributions as well as to rough categories structuring the contents of the interviews. These were 1) representations of country of origin/family; 2) migration experience; 3) sexuality/relationships; 4) work; and 5) interview interaction (these categories were made visible by using color-coded sticky notes). This wall provided a visual synopsis that yielded initial insights into the structurations of the interviews and visualized conversations and disjunctures within and between cases.

The second step aimed to gain a more detailed overview and understanding of the individual cases and their interconnections, enabling a more systematic comparison of themes across cases and a foundation upon which cases could then be selected for more detailed case reconstructions. This stage was guided by the coding techniques of Grounded Theory, which work precisely to extract similarities and differences within and among cases. Originally, Grounded Theory described both the research process (that is, the formulation of a research question, the sampling process, and the coding of the generated or collected data) and the 'grounded theory' emerging from the systematic analysis of the data. Here, I primarily made use of the sampling and coding principles of Grounded Theory, which I used to generate a meaningful sample, to organize the data, and to compare and interpret them. It has not, however, been my aim to systematically develop a 'grounded theory' organized around one single 'core category' as Grounded Theory suggests (Strauss and Corbin 1996: Chapter 8).

In their effort to develop a method that effectively works towards an understanding of the basic processes triggering social change and of the interactions between structure and agency, Anselm Strauss and Juliet Corbin (1996) suggest coding empirical data in several steps including open, axial, and selective coding. The distinction between these steps (especially between the first two) often remains conceptual rather than actual. 
In open coding, the text is broken down into segments (words, or short or long text sequences). A set of questions is thrown at the text (What? Who? How? When? Why? With what?), and comparisons are drawn among text segments (Böhm 2000). From this process, codes emerge; these are 'tagged' to the respective text segments and described in code memos. Next, in axial coding, these codes are differentiated, put into relation to each other, adapted and renamed, thereby becoming categories. The categories that are perceived to be of central importance are then intensely developed. At this stage, a coding paradigm is applied, which consists of four items: "conditions" (what conditions influence a phenomenon?); "interaction among the actors"; "strategies and tactics" (what interaction strategies are devised to address or deal with this phenomenon?); and "consequences" (what are the consequences of these interaction strategies, and how do they co-shape the phenomenon?). This paradigm can also be used to structure the data and to clarify relations between codes linked to this category (Strauss and Corbin 1996:78-92, Kelle 2005, Strauss 1987). In order to create an understanding of their hangings-together, in this stage, codes and categories that appeared to be central were also printed out and physically set into relation with each other in differing combinations. Finally, selective coding leads to a central phenomenon that represents a core category or variable, upon which the actual 'grounded theory' is then formulated. As indicated above, in this phase of the analysis, I focused on open and axial coding; selective coding was omitted since no single central phenomenon could be established, nor was one attempted to be formulated. Most data generated in this project was coded with Atlas.ti, mainly interview transcripts but also case-based memos and field notes (the first more comprehensively, the latter two only selectively).

In a third step (which was actually a going back and forth between steps two and three), sequences of selected cases were then analyzed in-depth using reconstructive sequential analysis techniques. Cases and sequences were once more selected using Theoretical Sampling, guided by the question of which data needed to be analyzed and presented in order to include all of the aspects relevant to the investigation. A simple but effective method I used was to select a case that seemed particularly rich and relevant and then work outwards from it, systematically adding cases to complement or contrast the previous cases according to emerging criteria. This procedure eventually met 'theoretical saturation,' a point reached when all salient aspects of an object of investigation seemed to have been addressed.

Reconstructive sequential analyses are neither an inductive nor a deductive but rather are an abductive procedure. What this meant in practice is shown in the following brief description of the sequential analysis process. Whenever possible, the sequential analyses were conducted collectively in our Materialgruppe (material group), which consisted of five graduate students from Social Anthropology and Geography (all from the Graduate School Gender Studies) who met weekly. At the outset of each session, we undertook an extremely rigorous reading of one word, of a very brief text sequence, or of a paralinguistic element (pause, laughter, hesitation, etc.). All discussion participants offered a range of readings of this word or sequence. These readings were generated by means of 'wild' associations and the free imagination of a variety of contexts - for instance, of the interviewee's social, political, or familial context, or considerations about the interview setting - that might have led to the utterance of this specific word or se- 
quence. Each participant of the reading group then pleaded for the reading she thought was most plausible. The group's task was to contest and disprove readings, until the group agreed on one or - very rarely - multiple valid readings. Still working on the same sequence, the same procedure was repeated with considerations of possible continuations of the text. Subsequently, the analysis was applied to the next word or brief sequence, now taking into account what had already been read and considered. After a while, the reading became quicker, and it was typically after reading an entire sequence (usually between ten and twenty lines) in such a way that the 'key' to a case, or 'case structure' (Fallstruktur) would emerge.

This extremely rigorous reading technique was inspired by the methodology of Objective Hermeneutics as formulated by Ulrich Oevermann (2002). We used a method close to Objective Hermeneutics in our group because in our experience it was not only the most painstaking but also the most productive method of analyzing and interpreting text. We became truly fascinated with the method after several instances in which we 'predicted' key issues and turns of an entire several-hour interview with accuracy after analyzing only the first ten lines of the interview transcript in a one-and-a-half-hour discussion session. At the same time, we also deviated from Objective Hermeneutics in several respects. The first divergence concerned the selection of the text sequence. Objective Hermeneutics requires the researcher to "take the bull by the horns" ("den Stier an den Hörnern packen"), as Oevermann likes to say, in the very first interview question. For instance, if researching mountain guides' professional self-conceptions, the first question in an interview should be something like "How did you come to be a mountain guide?" (Hungerbühler 2013). It is therefore fitting that Oevermann is adamant about the allimportance of the introductory interview sequence, and his analyses almost exclusively focus on this sequence. However, in research about sexuality, grabbing the bull by the horns is often not a valid option, and it was certainly not advisable in the context of this study. As a result, sexuality was rarely an explicit issue in the introductory sequence, so that a close reading of other sequences was conducted in addition to the first one. Second, Oevermann's method requires strict adherence to the semantics of words. By contrast, we found that strict adherence to the meaning of words can be problematic in a foreign language setting. We therefore placed less emphasis on the meaning of single words if we felt translation issues were at work. Third, Oevermann insists that all members of an analysis group must, without exception, agree on one interpretation of any given text. All of us being feminist scholars, we felt that feminist literature - as well as migration research, queer theory, and other perspectives - has amply documented that ambivalence, contradictions, and paradoxes are all part and parcel of what it means, for instance, to be woman and migrant and queer. In our group, therefore, we allowed more readily for multiple readings.

Such reconstructive social scientific approaches are distinguished by their "interpretative paradigm" (Blumer 1973). From this view, empirical data cannot speak for itself but always requires interpretation exceeding a merely descriptive level. Beyond recounting subjective experiences and self-interpretations ('first degree' constructions), a case reconstruction is performed that is a "reflexive, critical-analytical reconstruction of 'first degree' construction processes" (Dausien 2000:97, my translation). In other words, reconstructive methods frame the biographical narrative as a subjective construction, 
which is then reconstructed by the researcher from the point of view of specific research questions and theoretical perspectives. The reconstruction of a 'case' is thus a creative process of interpretation from which 'first degree' theoretical constructions emerge and reach beyond the 'first degree' constructions within the narratives.

Reconstructive methods are based on the assumption that the social world is structured and, as such, also structures experiences and narratives. Case reconstructions accordingly aim to analyze the principles structuring 'first degree' constructions as narrated by participants. On the one hand, this allows an understanding of the structuration of the biographers' subjective self-conceptions and actions; on the other hand, insights can be gained about the structurations of the conditions and social context within which these self-conceptions and actions take shape (Dausien 1994). This context is comprised of social, political, historical, economic, cultural, and other aspects of life as organized by dominant discourses. The structuration of biographers' narratives is highly contingent on the narrators' place within this context.

Following Bettina Dausien's suggestion (2007), the biographical narratives were thus considered on three levels: First, on the level of context, which means to acknowledge that the production of a narration is immersed in a broader socio-cultural framing that also features specific institutionalized narrative prescripts. Second, on the level of the multidimensional positionalities of individuals within this context, as well as the shifts and ruptures inherent in self-positionings (in other words: what stories were told and how). Third, on the level of the space-time of the interview interaction, taking into account the interests of both interviewer and interviewee and the relations of power between them. As Dausien writes: "With questions and theoretical guidelines, with the choice of the interview method, the 'setting' and their own communicative behavior in the interview situation, researchers are actively implicated in the construction of the 'gathered' life story" (Dausien 2000:105, my translation, see also Dausien 2005). This raises the question of the researcher's positionality, to which I turn in the next subchapter.

Finally, sequential analyses resulted in written analysis protocols. In the fourth and last step of the data analysis, these were merged with the code memos that resulted from the coding process according to Grounded Theory and condensed into a final text. Specific attention was given to anonymizing the material, which in this project was of particular importance given the intimate issues it addressed, the small size of Switzerland, and the attendant close-knit communities. This was achieved by changing interviewees' first and last names and sometimes additional information like place names. When quoting interviewees directly, small changes in language were sometimes made to make the text more understandable and to avoid the impression of linguistic inadequacy. Such an impression of inadequacy is created very quickly when transcribing oral text, even when speaking in one's mother tongue. 


\subsection{Some Thoughts on Positionality}

Inspired by feminist standpoint theory (Collins 1990, Haraway 1988, Harding 1991, Rose 1997), attention to the power relations between the researcher and the research subject have been at the heart of this study. Contending that knowledges are always partial and situated, feminist scholars have emphasized the role the positionality of the researcher plays in the process of producing knowledge. In the context of ethnographic work, this debate has addressed the question of the researcher's in- or outsider position with respect to the researched social group in particular, which, in line with feminist standpoint theory, is often a marginalized or deprivileged group.

In the beginning of my fieldwork, I wrote in my field book: "I throw myself into this queer transnational space, forever separated from it by the deep-seated knowledge that if worse comes to worse I can retreat into my safe white Swiss middle class world at any point in time." ${ }^{6}$ At the same time, there was no such 'exit' (Hannerz 2006:7) for me in terms of my sexuality; as a self-identified lesbian I am, like my interviewees, sexually non-conforming and, as such, subject to stereotypization and exclusions. There are thus, among others, two major contesting issues at stake here: the problem of the Western gaze on a colonial other, and the problems inherent to researching a social group from an insider position.

In terms of the first, I followed David Butz and Kathryn Besio's suggestion to analyze the generated empirical data in view of Mary Louise Pratt's notion of autoethnography. Autoethnography challenges the position from which privileged researchers situated in metropolitan academic institutions can "imagine ourselves as transcultural knowers and our subjects merely as 'Native informants"' (Butz and Besio 2004:351). ${ }^{7}$ Pratt uses autoethnography "to refer to those instances where members of colonized groups strive to represent themselves to their colonizers in ways that engage with colonizers' terms while also remaining faithful to their own self-understandings." As such, autoethnography describes "a particular mode of transcultural interaction by members of subordinate groups whose subjectivities are forged in the context of cross-cultural relations of domination" (ibid). The authors quote Mary Louise Pratt:

If ethnographic texts are a means by which Europeans represent to themselves their (usually subjugated) others, autoethnographic texts are those the others construct in response to or in dialogue with those metropolitan representations [...] autoethnography involves partial collaboration with and appropriation of the idioms of the conqueror. (Pratt 1992:7, quoted in Butz and Besio 2004:353)

As Pratt specifies in a later article:

Autoethnographic texts are not, then, what are usually thought of as autochthonous or 'authentic' forms of self-representation [...] Rather they involve a selective collaboration with and appropriation of idioms of the metropolis or conqueror. These are

$6 \quad$ Fieldbook entry July $14,2005$.

7 'Native informant' is a term Butz and Besio borrow from Gayatri Chakravorty Spivak (1999). 
merged or infiltrated to varying degrees with indigenous idioms to create self-representations intended to intervene in metropolitan modes of understanding.

(Pratt 1994:28, emphasis in the original, quoted in Butz and Besio 2004:353)

From this, Butz and Besio conclude that "autoethnography is not something researchers do, but something their research subjects do that they may want to study" (ibid:353). In other words, while there is no such thing as 'direct access' to 'native knowledge' gained by a transcultural knower-researcher, researchers have the possibility to analyze the ways in which Others represent themselves to the Same/researcher, appropriating, but also intervening in, the latter's definitions and discourses.

With Butz and Besio (2004:357), I argue that such transcultural interactions not only occur between colonizer and colonized but also when social scientists study historically subordinate groups within their Western societies, in this case immigrants in Switzerland. Applying an autoethnographic perspective to this study means that instead of framing research interviews as a conversation between a 'Native informant' and a 'transcultural knower-researcher', interviews are conceptualized as conversations between a metropolitan researcher and a transcultural knower-informant performing autoethnographic acts. Indeed, in the interviews it became very apparent that the interviewees were "transcultural knowers." As migrants, they were knowledgeable in at least two cultural settings. This bestowed upon them an epistemic advantage of a 'double vision,' that is, the self-reflexivity inherent in such insider/outsider positions. Black feminist critic bell hooks describes this point of view as follows: "Living as we did - on the edge - we developed a particular way of seeing reality. We looked both from the outside in and from the inside out [...] we understood both" (hooks 1994:vii, see also Collins 1990). ${ }^{8}$ The interviews were, crucially, structured by interviewees' attempts to translate 'their cultures' to me. Hence, an autoethnographic perspective opens up the text on the level of the interaction happening between interviewer and interviewee and the power relations inherent in this encounter. As such, it enables the detection and naming of colonial effects, which is a prerequisite for postcolonial inquiries that seek to "go beyond understanding the continuing effects of colonialism and engage actively in processes that work to create a past-colonial future (one in which the archetypal moment of transcultural relations is no longer colonialism)" (Butz and Besio 2004:355).

The queer sexuality which I 'shared' with research participants raised different methodological issues altogether. As discussed earlier, definitions of sexuality are always already implicated in definitions of nationalities, ethnicities, and cultures. However, they

In his analysis of the Indian 'second migration generation' in Switzerland, Rohit Jain problematizes this metaphor of "living between two worlds" as a subjectivation logic rooted in the biopolitical assimilation project of the modern Swiss nation (see also Chapter 6.1.4). "In the dominant narrative of the 'culture conflict," Jain writes, "members of the 'second generation' were naturalized as existences in crisis torn between cultural essentialist entities of the national 'own' and the assimilationist 'other' [...]" (]ain 2018:96, my translation). While this subjectivation logic of the 'second generation' certainly differs from that of 'first generation' immigrants in important ways, the figure of 'existences in crisis' as torn between cultures can equally be found in discourses around first generation immigrants. 
are also co-constructive and co-constructions of other aspects of the social, such as gender, class, and others. This eventually renders sexual positionalities difficult to 'share.' At the same time, it is an indisputable fact that my identification as a lesbian opened doors, increased the willingness of potential interviewees to participate, established pre-emptive trust, and triggered curiosities. There was often a sense of 'us' established in research interactions, coproduced by myself and the interviewee, enabled perhaps by the myth of the global queer family. Such a "tacit assumption of sameness" (Hurd and McIntyre 1996:78), however, risks distancing both interviewer and interviewee from selfreflection. Consider research participant Augusta Wakari's following statement: "Ah for me it's- it's the same with you right? I mean somebody starts talking to me about their husbands and you know- I'm just like 'Okay this is just not my world, I can't relate, I just can't." Instead of asking why, exactly, a relation cannot be established to heterosexual women speaking about their husbands, I left this comment unquestioned. No doubt I was thinking, "Yes, I know exactly what you mean," which precluded an examination of the differences between my own and the interviewee's view on the issue.

Another effect of this assumed sameness with regard to sexuality was interviewees' interest in my own story. This interest was especially marked in the case of interviewees who had not talked much about their homosexuality before the research interview. In these interactions, our roles would typically be reversed towards the end of the interview, with interviewees asking about my 'coming out' (especially how my parents had reacted), my relationship (where mainly its duration and its character (monogamous?) were of interest), and occasionally about how my German partner dealt with certain immigration issues. These questions made me as vulnerable as my interviewees had been a moment ago when I was doing the asking. At the same time, I often emerged as a sort of 'expert' on lesbianism in these conversations. Interviewees who had not had much contact with Swiss lesbians before were particularly interested in hearing how Swiss lesbians 'are,' and my perspective was subsequently sometimes referred to as the norm against which interviewees then defined their own stories and relationships, sometimes from a somewhat defensive stance. I was moreover addressed as an 'expert' on legal aspects of queer migration. However, while the "tacit assumption of sameness" obstructed access to answers to questions never asked, the mechanisms addressed here - the reversal of roles and its implications on the power relations during the interview - can be exposed and analyzed.

The question of 'shared' queer positionality was further complicated by the flirtations and the negotiations of personal relationships before, during and after the interviews, which raises the issue of sexuality and erotic subjectivity in ethnographic fieldwork. The significance of this matter is of course not limited to queer researchers but concerns any ethnographer in the field, no matter their sexual preference. Nevertheless, this issue has largely been neglected, or actively ignored, by social anthropologists (Kulick and Wilson 1995, Lewin and Leap 1996) and geographers (Cupples 2002), who have both preferred to look at the "sex lives of others" while remaining "very tight-lipped about their own sexuality" (Kulick 1995:3). However, Julie Cupples contends that if it is true that, as queer geographers have suggested, "sexuality both produces space and permeates social life, then the fieldwork experience is no different" (Cupples 2002:382). In her article about sex and sexuality in geographical fieldwork, she highlights the im- 
portance of considering sexuality and erotic subjectivity, especially in cross-cultural settings. For this she names three reasons. First, since a researcher cannot shed her sexuality when entering the field, sexuality should be acknowledged as a (often crucial) factor that influences the co-production of the social field in which empirical data is generated. Engaging with the issue of sexuality and erotic subjectivity in research encounters enables conceptualizations of positionalities that go beyond essentializing attributes (ethnicity, gender, and so on), which can moreover "challenge the distance between us and them" (ibid:383). In a similar vein, Don Kulick argues that addressing desire in the field is epistemologically productive, since an erotic relationship between the ethnographer and her subject(s), whether consummated sexually or not, represents "one especially poignant means through which anthropologists become aware of themselves as positioned, partial, knowing selves" (Kulick 1995:18). This especially also includes being aware of the "racist and colonialist conditions which make possible the unidirectional discourse about the sexuality of the people we study" (ibid:4). Second, Cupples argues that acknowledging that the field itself can be seductive allows for a conscious instrumentalization of this very seductiveness, which enables more powerful insights about it. ${ }^{9}$ A third reason to engage with erotic subjectivity in the field, according to Cupples, is the fact that "we do not only position ourselves in the field, we are also positioned by those whom we research." Even when as researchers we attempt to put aside our sexualities, we will always also be perceived as sexualized subjects (Cupples 2002:383). The data generated in this project provided ample evidence of this. It has been my intention to reflect on these dynamics throughout the analyses, but often felt that I have failed to exploit the full potential of this perspective.

In sum, the in/outsider position has to be understood as a complex and dynamic process rather than a fixed status (Naples 2003). I contend with Kulick that "individual relationships in the field are obviously the ongoing outcomes of dynamics that cannot be reduced to global political inequalities" (Kulick 1995:24). An ethnographer's positionality is contingent on the meeting-up of two or more subjects (researcher and researched) with different stories-so-far and multiple identities, which in the context of fieldwork experience as a lived experience cannot be reduced to a dualistic opposition of Self and Other. 'Lived experience' thereby exceeds the notion of multiple identities since neither the researchers nor the researched can ever fully understand or know their own Selves and positionalities (Rose 1997).

Within the debate around the ethical problems inherent in 'representing the Other', a recurring question has been whether it would be better for the feminist ethnographer our sexual desire for the other constitutes a transcendence of self and other or is a result of racist fantasies, of wanting to possess the other?" (Cupples 2002:385). In this context, Kulick cautions that "it would be unfortunate if readers [of his edited book] were left with the impression that the purpose of this book is to encourage anthropologists to rush off into the field and have sex with their informants." Asserting that the structural conditions that make an encounter (sexual or not) between an ethnographer and their subjects possible in the first place are highly unequal, Kulick reiterates that his point is "precisely that sexuality seems to have the potential of bringing into theoretical and political focus exactly those asymmetrically ordered conditions" (Kulick 1995:22). 
to stay home. Queer theorists in particular have remained very reluctant to 'get dirty' in the field and continue to tend towards cultural studies approaches. Queer ethnography is a latecomer to queer studies exactly because it has been marginalized, and has marginalized itself, by framing ethnographic work focused on issues of sexuality as a "voyeuristic fantasy of the anthropologist as empiricist" (Weiss 2011:650). Drawing on Kath Weston, Margot Weiss argues that such a view "consolidates a data-theory divide that maps on to the social sciences-humanities divide in terms of academic labor," which is reproductive of "the fantasy of data as 'raw' data, with no attention to the ways data are used, derived, or produced" (ibid). With Weiss and other queer scholars (e.g. Boellstorff 2007b, Dankwa 2014), in contrast, I advocate the inclusion of ethnographic studies in the production of queer theoretical knowledge. As Jasbir Puar points out, "given the figure of the 'discerning gay traveler,' queers of color returning to the homeland, and activist-tourist collaborations, the relationships among cosmopolitanism, nationalism, and modernity, as routed through sexual politics and pleasure, are clearly not as convenient as a distinction between staying home or not" (Puar 2002a:125-126).

In addition to my attempt to reflect on my own positionality in the field, I have aimed to apply research methods and writing techniques that work to 'give a voice.' Literally giving a voice is particularly difficult in a context in which interviews are not given in the mother language. This was one determining factor in the decision to apply reflexive photography, which works towards giving a gaze instead (see above). Indeed, the significance of creating a visual representation of one's life-world as a creative process was positively reflected in many interviewees' comments about the task. As to writing techniques, I strove to make this an open and transparent text (Decena 2012:4). Interviews are deliberately quoted at some length and are included in both the original language and my translation into English. This renders the translations and interpretations more transparent, and thus contestable, for those readers proficient in both languages. While the interpretations are ultimately my own, these techniques have been applied with the intention of working towards "ways of writing about lives so as to constitute them as less other" (Abu-Lughod 1991:149) and to produce 'traiterous knowledges' (Harding 1991) as a non-migrant ally.

I now proceed to the interview analyses. 
